\title{
Stable isotopes as ecological tracers: an efficient method for assessing the contribution of multiple sources to mixtures
}

\author{
M. N. Bugalho' ${ }^{1}$ P. Barcia ${ }^{2}$, M. C. Caldeira ${ }^{3,4}$, and J. O. Cerdeira ${ }^{3,5}$ \\ ${ }^{1}$ Centro de Ecologia Aplicada "Baeta Neves”, Instituto Superior de Agronomia, Universidade Técnica de Lisboa, Portugal \\ ${ }^{2}$ Faculdade de Economia, Universidade Nova de Lisboa, Lisboa, Portugal \\ ${ }^{3}$ Centro de Estudos Florestais, Instituto Superior de Agronomia, Universidade Técnica de Lisboa, Portugal \\ ${ }^{4}$ Departamento Florestal, Instituto Superior de Agronomia, Universidade Técnica de Lisboa, Portugal \\ ${ }^{5}$ Departamento de Matemática, Instituto Superior de Agronomia, Universidade Técnica de Lisboa, Portugal
}

Received: 7 April 2008 - Published in Biogeosciences Discuss.: 9 June 2008

Revised: 14 August 2008 - Accepted: 20 August 2008 - Published: 25 September 2008

\begin{abstract}
Stable isotopes are increasingly being used as tracers of ecological processes potentially providing relevant information to environmental management issues. An application of the methodology consists in relating the stable isotopic composition of a sample mixture to that of sources. The number of stable isotopes, however, is usually lower than that of potential sources existing in an ecosystem, which creates mathematical difficulties in correctly tracing sources. We discuss a linear programming model which efficiently derives information on the contribution of sources to mixtures for any number of stable isotopes and any number of sources by addressing multiple sources simultaneously. The model identifies which sources are present in all, present in a subset of the samples or absent from all samples simultaneously and calculates minimum and maximum values of each source in the mixtures. We illustrate the model using a data set consisting of the isotopic signatures of different plant sources ingested by primary consumers in tropical riverine habitat in Asia. The model discussed may contribute to extend the scope of stable isotopes methodology to a range of new problems dealing with multiple sources and multiple tracers. For instance, in food web studies, if particular organic matter sources disappear or decrease in availability (e.g. climate change scenarios) the model allows simulation of alternative diets of the consumers providing potentially relevant information for managers and decision makers.
\end{abstract}

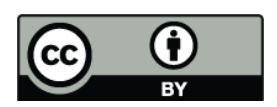

Correspondence to: M. N. Bugalho (migbugalho@isa.utl.pt)

\section{Introduction}

Stable isotopes are naturally occurring chemical forms of the same element that differ in their molecular masses. Due to differential masses, stable isotopes are discriminated in physical, chemical and biological reactions: the lighter and more abundant isotopes (e.g. ${ }^{12} \mathrm{C}$ ) are more reactive than heavier ones (e.g. ${ }^{13} \mathrm{C}$ ). As a consequence reaction products tend to be depleted in lighter isotopes and un-reacted products tend to be enriched in heavier isotopes (McKechnie, 2004). This property makes stable isotopes useful as natural integrators and tracers of ecological processes explaining their increasing use in ecological research and environmental management (West et al., 2006).

The use of stable isotopes as tracers requires that the different potential sources have distinct isotopic values and that stable isotopes do not undergo significant fractionation (Dawson et al., 2002). In many fields of science, stable isotopes are used as tracers to determine the proportional contributions of several sources to a mixture (Phillips and Gregg 2003). Applications range from water use by plants to the study of migration and diets in animal ecology (Querejeta et al., 2007; Cherel et al., 2005).

Stable isotope measurements of animal tissues may give information on the animal diet or location of feeding provided that isotope signatures vary among potential dietary components and locations of feeding (Cerling et al., 2006). Quite often, particularly in diet studies (e.g. Ben-David, Flyn and Schell, 1997), the number of potential food sources is much higher than the number of stable isotopes which creates mathematical difficulties in identifying and quantifying the contribution of each source to a particular mixture or sample of the animal tissue analysed, because infinitively many multiple solutions are possible.

Published by Copernicus Publications on behalf of the European Geosciences Union. 
Initial models for tracing stable isotopes were limited to consider one tracer at a time (e.g. van Dover et al., 1992). More recently, other models allowed for a more complex set of potential sources to be considered (Phillips and Gregg, 2003; Lubetkin and Simenstad, 2004). Current approaches use mixing models to decipher source contributions to a mixture when the number of sources is higher or equal to that of stable isotopes +1 . For instance, IsoSource (Phillips and Gregg, 2003), the most commonly used algorithm, iteratively tests within a specified tolerance, all possible source contributions to a mixture. Specifically, a source increment $s$ is user defined (e.g., entering a value of $s=1 \%$ ) and every combination of multiples of $s$ of each source adding up to $100 \%$ is tested as a feasible solution (within the given tolerance) to a particular mixture. This approach has been used successfully in a number of studies (Inger et al., 2006; Benstead et al., 2006) but becomes computationally demanding with an increasing number of sources. For instance, an example of seven sources and two isotopes would require examining more than 1.7 billion partitions at $1 \%$ increment or over 32 million partitions at $2 \%$ increments (Lubtekin and Simenstad, 2004).

Lubtekin and Simenstad (2004) proposed a model specifically addressed to food webs which only enumerates the (basic) solutions corresponding to mixtures where the number $n$ of sources does not exceed the number of tracers $i$ plus 1 . This gives a set $S$ of $\left(\begin{array}{c}n \\ i+1\end{array}\right)=\frac{n(n-1) \ldots(n-i)}{(i+1) i \ldots 1}$ mixtures, from which some mathematically possible "nonsensical mixtures" (i.e. those not having all fractions of sources combinations comprised between 0 and 1) may have to be excluded. The solutions in $S$ are those that define the limits of the region (of the $n$-dimensional Euclidean space) where the remaining feasible solutions are, which considerably reduces the size of the output relatively to that of IsoSource. For instance, for the same example of seven sources and two stable isotopes, the approach suggested by Lubetkin and Simenstad (2004) would take 35 corner points to delineate the outer boundaries of the solution range. Lubetkin and Simenstad (2004) also consider the arithmetic mean of the solutions in $S$ as a representative mixture.

Approaches such as those describe above based on iterative models are rather inefficient because

1. they generate a large number of solutions from which the insensible solutions are subsequently removed and

2. frequently require grouping of sources to make calculations feasible.

Instead of an iterative model we use a simple linear programming algorithm which efficiently derives relevant information on source contributions to mixtures and addresses multiple samples simultaneously. The model provides the minimum and maximum contributions of each source among all the (infinitely many) possible mixtures and efficiently generates qualitative information on the simultaneous presence of sources in the mixtures. Addressing multiple samples simultaneously allow addressing questions such as: Which sources are present in all mixtures? Which sources are absent from all mixtures? Or which sources are certainly present in particular mixtures?

We illustrate this approach with an example of diet composition, by applying the model to a data set used by Benstead et al. (2006), consisting of the isotopic signatures of different organic matter sources ingested by primary consumers in a tropical riverine habitat in Asia.

\section{Material and methods}

\subsection{The data base}

For computational experiments we used the data base provided in the Ecological Archives E087-018-A2 for the Ecology paper by Benstead et al. (2006). The database consists of:

1. the isotopic signatures of sources of organic matter (mangrove litter, freshwater swamp-forest litter, seagrasses, seagrass epiphytes, and marine particulate organic matter) from four estuaries in Kosrae, Federated States of Micronesia, that are consumed by primary consumers (fishes and crabs) in a tropical riverine habitat; and

2. the isotopic signatures of samples of tissue collected from primary consumers (the mixtures).

Data were collected independently in 4 different study areas. Sources of organic matter included epiphyte (Ep) and nonepiphyte forms of seagrasses as well as samples of individual species collected at riverine $(\mathrm{R})$, interior $(\mathrm{I})$ and fringe $(\mathrm{F})$ habitat. Primary consumers include fish species from mangrove and reef flat areas as well as mangrove crabs. We used stable isotopes $\delta^{13} \mathrm{C}$ and $\delta^{34} \mathrm{~S}$ to run our model, as Benstead et al. (2006) did. We did not consider the marine particulate organic matter source as its $\delta^{13} \mathrm{C}$ and $\delta^{34} \mathrm{~S}$ isotopic signatures were taken from the literature and not directly measured and also because this source was irrelevant to the diet of consumers analysed (Benstead et al., 2006). We also did not consider the $\delta^{15} \mathrm{~N}$ values for the organic matter sources due to their relative uniformity in the mean values at each site (even after correcting for fractionation) which limited the utility of these data (Benstead et al., 2006).

The latter authors grouped individual organic matter sources into 5 different groups: mangrove leaf litter, freshwater swamp-forest leaf litter, seagrasses, seagrass epiphytes and marine particulate organic matter. We did not group organic matter sources as

1. the model can handle any number of sources, 
2. to avoid any assumptions of a priori grouping of sources (this allows leaving this decision for posterior analysis after interpretation of the model output) and

3. because we wanted to explicitly address all individual samples simultaneously (in spite of magnitude of differences of their isotope signatures).

The model was run for each of the 4 study areas. We used information on the isotopic signatures of 19 primary consumers and 14 organic matter sources in study area Yela; 13 primary consumers and 12 organic matter sources in study area Okat; 9 primary consumers and 19 organic matter sources in study area Finkol; 14 primary consumers and 17 sources of organic matter in study area Yeseng.

\subsection{The model}

The model, a variant of the method of Barcia et al. (2007) for estimating diet composition of herbivores using natural markers in plant cuticules, uses linear programming to classify (see below) and determine the maximum and minimum proportions of each source in each sample. (An implementation of the model is available at http://www.isa.utl.pt/ $\sim$ orestes/LP_Tracer/) More precisely, if $S_{i}$ is the column vector of the isotope signatures of source $i(i=1, \ldots, n), M$ the column vector containing the isotope signatures of a sample and $x_{i}$ the variable indicating the contribution of source $i$ to the sample, the maximum and minimum values of each $x_{i}$ is subject to:

$$
\sum_{i} S_{i} x_{i}=M
$$

$\sum_{i} x_{i}=1$

$x_{i} \geq 0$, for $i=1, \ldots, n$

are determined. This can be easily achieved using any linear programming solver (e.g. the site http://www-new.mcs.anl. gov/otc/Guide/SoftwareGuide/Categories/linearprog.html includes links to several linear programming software packages).

For each sample mixture (e.g. consumer), the $2 \times n$ maximum and minimum solutions obtained this way are highly meaningful for data interpretation (e.g. Demopoulos, Fry and Smith 2007), among an infinite list of feasible solutions. Combined for all samples these solutions allow the classification of sources. If the maximum value of the proportion of a given source is zero for all the samples then we can conclude that that source is absent from every mixture, and it can be omitted from further consideration. If the minimum value is greater than zero we can conclude that the source is necessary to explain that sample. A source is mandatory if that source is necessary to explain all samples simultaneously. A source is conditional mandatory if that source is necessary to explain at least one, but not every sample. A (non absent) source is optional if the minimum value is zero for every sample. Unless the maximum value is zero, it is not possible to conclude that an optional source is indeed part of the mixture.

Beyond this qualitative classification, the solutions obtained allow deriving relevant information. Relatively high minimum values indicate significant mandatory or conditional mandatory sources, whilst low maximum values indicate relatively low importance sources. When minimum and maximum values coincide a reliable estimate of the source contribution is achieved.

\section{Results}

A graphical solution is presented for each estuary (Fig. 1). The polygon for each study area is the convex hull of the sources (i.e. the smallest convex set containing all the sources). Samples falling outside the polygon bounds give rise to "nonsensical mixtures" and were excluded from the analyses: Epinephelus merra, Caranx melampygus, Aphareus furca, Lutjanus monostigma and Kyphosus cinerascens in study area Yela; Liza vaigiensis, Caranx ignobilis, Lutjanus semicinctus and Moolgarda engeli in study area Okat; Moolgarda seheli, Cephalopholis leopardus, E. merra, Lethrinus harak in study area Finkol; and Kyphosus vaigiensis and Sargocentron punctatissimum in study area Yeseng. The user, however, can use his/her ecological sensibility to decide if some of the sources should be included in the analysis by changing the tolerance value of the model (see the help menu of model implementation). Tables 1 to 4 summarize main aspects of the solutions produced by our model, identifying minimum and maximum source contributions to consumer diets in each estuary. No sources were classified as absent in any of the 4 study areas. (Indeed, when using 2 markers only, a source would only be absent if, and only if, all mixtures were aligned along a segment to which that source does not belong). Five organic matter sources were classified as conditional mandatory (study areas Yela, Yeseng and Okat) and 1 as mandatory (study area Okat). All remaining sources were classified as optional.

In study area Yela, Xylocarpus granatum-R was included in the diet of Siganus vermiculatus with a value between 3\% and 26\% (Table 1). This justifies its classification as conditional mandatory (Table 1). The other sources were classified as optional, and we can not conclude if they were part of the diet of any consumer. However, low positive maximum values of an optional source imply it has low importance in the diet. For instance, none of the mangrove trees occurs in the diet of $L$. vaigiensis with more than $10 \%$ (Table 1). Similarly, in the diet of $S$. vermiculatus, the sources Rhizophora apiculata-I, Nypa fruticans-R and N. fruticans-I did not exceed $7 \%, 6 \%$ and $7 \%$, respectively. Conversely, the seagrasses $E n$ halus acoroides or Thalassia hemiprichii entered, with high 
Table 1. Source category and minimum and maximum proportions of organic matter source species in the diet of consumers at Study Area Yela as estimated by stable isotopes $\delta^{13} \mathrm{C}$ and $\delta^{34} \mathrm{~S}$.

\begin{tabular}{|c|c|c|c|c|c|c|c|c|c|c|c|c|c|c|c|}
\hline \multirow[t]{2}{*}{ Source Species } & \multirow[t]{2}{*}{ Category } & \multicolumn{14}{|c|}{ Consumer Species } \\
\hline & & L. vaigiensis & S. praslin & C. ignobilis & L. equulus & L. fulvus & L. harak & M. flavolineatus & P. indicus & $U$. arge & Oxyeleotris sp. & S. vermiculatus & S. barracuda & S. qenie & S. serrata \\
\hline \multicolumn{16}{|l|}{ Mangrove Trees } \\
\hline \multirow{2}{*}{ B. gymnorhiza-R } & $\mathrm{O}$ & 0.00 & 0.00 & 0.00 & 0.00 & 0.00 & 0.00 & 0.00 & 0.00 & 0.00 & 0.00 & 0.00 & 0.00 & 0.00 & 0.00 \\
\hline & & 0.08 & 0.37 & 0.41 & 0.29 & 0.33 & 0.22 & 0.33 & 0.39 & 0.28 & 0.66 & 0.14 & 0.34 & 0.24 & 0.60 \\
\hline \multirow[t]{2}{*}{ B. gymnorhiza-I } & $\mathrm{o}$ & 0.00 & 0.00 & 0.00 & 0.00 & 0.00 & 0.00 & 0.00 & 0.00 & 0.00 & 0.00 & 0.00 & 0.00 & 0.00 & 0.00 \\
\hline & & 0.09 & 0.40 & 0.44 & 0.31 & 0.36 & 0.24 & 0.35 & 0.41 & 0.30 & 0.70 & 0.14 & 0.36 & 0.24 & 0.64 \\
\hline \multirow[t]{2}{*}{ R. apiculata $-\mathrm{R}$} & $\mathrm{O}$ & 0.00 & 0.00 & 0.00 & 0.00 & 0.00 & 0.00 & 0.00 & 0.00 & 0.00 & 0.00 & 0.00 & 0.00 & 0.00 & 0.00 \\
\hline & & 0.09 & 0.36 & 0.46 & 0.32 & 0.37 & 0.25 & 0.37 & 0.43 & 0.31 & 0.70 & 0.12 & 0.38 & 0.22 & 0.66 \\
\hline \multirow[t]{2}{*}{ R. apiculata-I } & $\mathrm{O}$ & 0.00 & 0.00 & 0.00 & 0.00 & 0.00 & 0.00 & 0.00 & 0.00 & 0.00 & 0.00 & 0.00 & 0.00 & 0.00 & 0.00 \\
\hline & & 0.10 & 0.21 & 0.49 & 0.34 & 0.27 & 0.22 & 0.39 & 0.41 & 0.33 & 0.41 & 0.07 & 0.33 & 0.13 & 0.52 \\
\hline \multirow[t]{2}{*}{ R. apiculata- $\mathrm{F}$} & $\mathrm{O}$ & 0.00 & 0.00 & 0.00 & 0.00 & 0.00 & 0.00 & 0.00 & 0.00 & 0.00 & 0.00 & 0.00 & 0.00 & 0.00 & 0.00 \\
\hline & & 0.10 & 0.39 & 0.50 & 0.35 & 0.41 & 0.27 & 0.40 & 0.47 & 0.34 & 0.76 & 0.13 & 0.42 & 0.23 & 0.73 \\
\hline \multirow[t]{2}{*}{ X. granatum $-\mathrm{R}$} & C & 0.00 & 0.00 & 0.00 & 0.00 & 0.00 & 0.00 & 0.00 & 0.00 & 0.00 & 0.00 & 0.03 & 0.00 & 0.00 & 0.00 \\
\hline & & 0.10 & 0.46 & 0.33 & 0.21 & 0.41 & 0.27 & 0.40 & 0.42 & 0.34 & 0.57 & 0.26 & 0.42 & 0.31 & 0.45 \\
\hline \multirow[t]{2}{*}{ N. fruticans $-\mathrm{R}$} & $\mathrm{O}$ & 0.00 & 0.00 & 0.00 & 0.00 & 0.00 & 0.00 & 0.00 & 0.00 & 0.00 & 0.00 & 0.00 & 0.00 & 0.00 & 0.00 \\
\hline & & 0.09 & 0.17 & 0.43 & 0.32 & 0.21 & 0.18 & 0.32 & 0.33 & 0.29 & 0.33 & 0.06 & 0.26 & 0.10 & 0.41 \\
\hline \multirow[t]{2}{*}{ N. fruticans-I } & $\mathrm{O}$ & 0.00 & 0.00 & 0.00 & 0.00 & 0.00 & 0.00 & 0.00 & 0.00 & 0.00 & 0.00 & 0.00 & 0.00 & 0.00 & 0.00 \\
\hline & & 0.09 & 0.21 & 0.47 & 0.33 & 0.26 & 0.22 & 0.38 & 0.41 & 0.32 & 0.40 & 0.07 & 0.33 & 0.12 & 0.51 \\
\hline \multirow[t]{2}{*}{ Н. пипи } & $\mathrm{O}$ & 0.00 & 0.00 & 0.00 & 0.00 & 0.00 & 0.00 & 0.00 & 0.00 & 0.00 & 0.00 & 0.00 & 0.00 & 0.00 & 0.00 \\
\hline & & 0.08 & 0.38 & 0.42 & 0.27 & 0.34 & 0.23 & 0.34 & 0.40 & 0.29 & 0.67 & 0.19 & 0.35 & 0.26 & 0.58 \\
\hline \multicolumn{16}{|c|}{ Freshwater Swamp Trees } \\
\hline \multirow[t]{2}{*}{ B. racemosa } & $\mathrm{O}$ & 0.00 & 0.00 & 0.00 & 0.00 & 0.00 & 0.00 & 0.00 & 0.00 & 0.00 & 0.00 & 0.00 & 0.00 & 0.00 & 0.00 \\
\hline & & 0.09 & 0.41 & 0.43 & 0.28 & 0.37 & 0.25 & 0.36 & 0.43 & 0.31 & 0.72 & 0.20 & 0.38 & 0.27 & 0.59 \\
\hline \multicolumn{16}{|c|}{ Seagrasses and epiphytes } \\
\hline \multirow[t]{2}{*}{ E.acoroides } & $\mathrm{O}$ & 0.00 & 0.00 & 0.00 & 0.00 & 0.00 & 0.00 & 0.00 & 0.00 & 0.00 & 0.00 & 0.00 & 0.00 & 0.00 & 0.00 \\
\hline & & 0.81 & 0.63 & 0.55 & 0.38 & 0.65 & 0.76 & 0.64 & 0.59 & 0.69 & 0.34 & 0.78 & 0.64 & 0.75 & 0.38 \\
\hline \multirow[t]{2}{*}{ T. hemprichii } & $\mathrm{O}$ & 0.00 & 0.00 & 0.00 & 0.00 & 0.00 & 0.00 & 0.00 & 0.00 & 0.00 & 0.00 & 0.00 & 0.00 & 0.00 & 0.00 \\
\hline & & 0.88 & 0.64 & 0.57 & 0.40 & 0.68 & 0.79 & 0.67 & 0.61 & 0.72 & 0.35 & 0.78 & 0.66 & 0.76 & 0.39 \\
\hline \multirow[t]{2}{*}{ E. acoroides Ep. } & $\mathrm{O}$ & 0.00 & 0.00 & 0.00 & 0.00 & 0.00 & 0.00 & 0.00 & 0.00 & 0.00 & 0.00 & 0.00 & 0.00 & 0.00 & 0.00 \\
\hline & & 0.38 & 0.45 & 0.62 & 0.74 & 0.56 & 0.47 & 0.69 & 0.63 & 0.72 & 0.35 & 0.15 & 0.64 & 0.27 & 0.43 \\
\hline \multirow{2}{*}{ T. hemprichii Ep. } & $\mathrm{O}$ & 0.00 & 0.00 & 0.00 & 0.00 & 0.00 & 0.00 & 0.00 & 0.00 & 0.00 & 0.00 & 0.00 & 0.00 & 0.00 & 0.00 \\
\hline & & 0.27 & 0.32 & 0.58 & 0.71 & 0.40 & 0.33 & 0.60 & 0.55 & 0.54 & 0.31 & 0.11 & 0.49 & 0.19 & 0.39 \\
\hline
\end{tabular}

Letters mean: O - Optional; C - Conditional mandatory; Ep - Epiphytes; R - Riverine; I - Interior; F - Fringe.

Table 2. Source category and minimum and maximum proportions of organic matter source species in the diet of consumers at Study Area Okat as estimated by stable isotopes $\delta^{13} \mathrm{C}$ and $\delta^{34} \mathrm{~S}$.

\begin{tabular}{|c|c|c|c|c|c|c|c|c|c|c|}
\hline \multirow[t]{2}{*}{ Source species } & \multirow[t]{2}{*}{ Category } & \multicolumn{9}{|c|}{ Consumer species } \\
\hline & & M. seheli & E. merra & L. equulus & L. fulvus & L. harak & P. indicus & U. vittaus & S. randalli & S. serrata \\
\hline \multicolumn{11}{|l|}{ Mangrove trees } \\
\hline B. gymnorhiza- $\mathrm{R}$ & $\mathrm{O}$ & 0.00 & 0.00 & 0.00 & 0.00 & 0.00 & 0.00 & 0.00 & 0.00 & 0.00 \\
\hline \multirow[t]{2}{*}{ B. gymnorhiza-I } & $\mathrm{O}$ & 0.00 & 0.00 & 0.00 & 0.00 & 0.00 & 0.00 & 0.00 & 0.00 & 0.00 \\
\hline & & 0.04 & 0.00 & 0.00 & 0.27 & 0.17 & 0.22 & 0.00 & 0.28 & 0.32 \\
\hline R. apiculata-R & $\mathrm{O}$ & 0.00 & 0.00 & 0.00 & 0.00 & 0.00 & 0.00 & 0.00 & 0.00 & 0.00 \\
\hline R. apiculata-I & & 0.05 & 0.00 & 0.00 & 0.22 & 0.22 & 0.27 & 0.00 & 0.26 & 0.42 \\
\hline \multirow[t]{2}{*}{ R. apiculata $-\mathrm{F}$} & $\mathrm{O}$ & 0.00 & 0.00 & 0.00 & 0.00 & 0.00 & 0.00 & 0.00 & 0.00 & 0.00 \\
\hline & & 0.05 & 0.00 & 0.00 & 0.32 & 0.24 & 0.32 & 0.00 & 0.38 & 0.46 \\
\hline \multirow[t]{2}{*}{ S. alba-R } & $\mathrm{O}$ & 0.00 & 0.00 & 0.00 & 0.00 & 0.00 & 0.00 & 0.00 & 0.00 & 0.00 \\
\hline & & 0.04 & 0.00 & 0.00 & 0.31 & 0.17 & 0.23 & 0.00 & 0.29 & 0.34 \\
\hline N. fruticans $-\mathrm{R}$ & $\mathrm{O}$ & 0.00 & 0.00 & 0.00 & 0.00 & 0.00 & 0.00 & 0.00 & 0.00 & 0.00 \\
\hline H. пипи & & 0.02 & 0.00 & 0.00 & 0.20 & 0.11 & 0.15 & 0.00 & 0.18 & 0.21 \\
\hline \multicolumn{11}{|c|}{ Freshwater Swamp Trees } \\
\hline \multirow[t]{2}{*}{ B. racemosa } & $\mathrm{C}$ & 0.00 & 0.08 & 0.00 & 0.00 & 0.00 & 0.00 & 0.00 & 0.00 & 0.00 \\
\hline & & 0.02 & 0.08 & 0.00 & 0.18 & 0.10 & 0.13 & 0.00 & 0.17 & 0.20 \\
\hline \multicolumn{11}{|c|}{ Seagrasses and epiphytes } \\
\hline \multirow[t]{2}{*}{ E. acoroides } & M & 0.40 & 0.92 & 0.56 & 0.58 & 0.34 & 0.57 & 0.63 & 0.55 & 0.28 \\
\hline & & 0.43 & 0.92 & 0.56 & 0.71 & 0.46 & 0.72 & 0.63 & 0.70 & 0.52 \\
\hline \multirow[t]{2}{*}{ E. acoroides Ep. } & $\mathrm{C}$ & 0.52 & 0.00 & 0.44 & 0.00 & 0.28 & 0.00 & 0.37 & 0.00 & 0.00 \\
\hline & & 0.58 & 0.00 & 0.44 & 0.24 & 0.56 & 0.29 & 0.37 & 0.29 & 0.52 \\
\hline
\end{tabular}

Letters mean: O - Optional; C - Conditional mandatory; M - Mandatory; Ep - Epiphytes; R - Riverine; I - Interior; F - Fringe. 

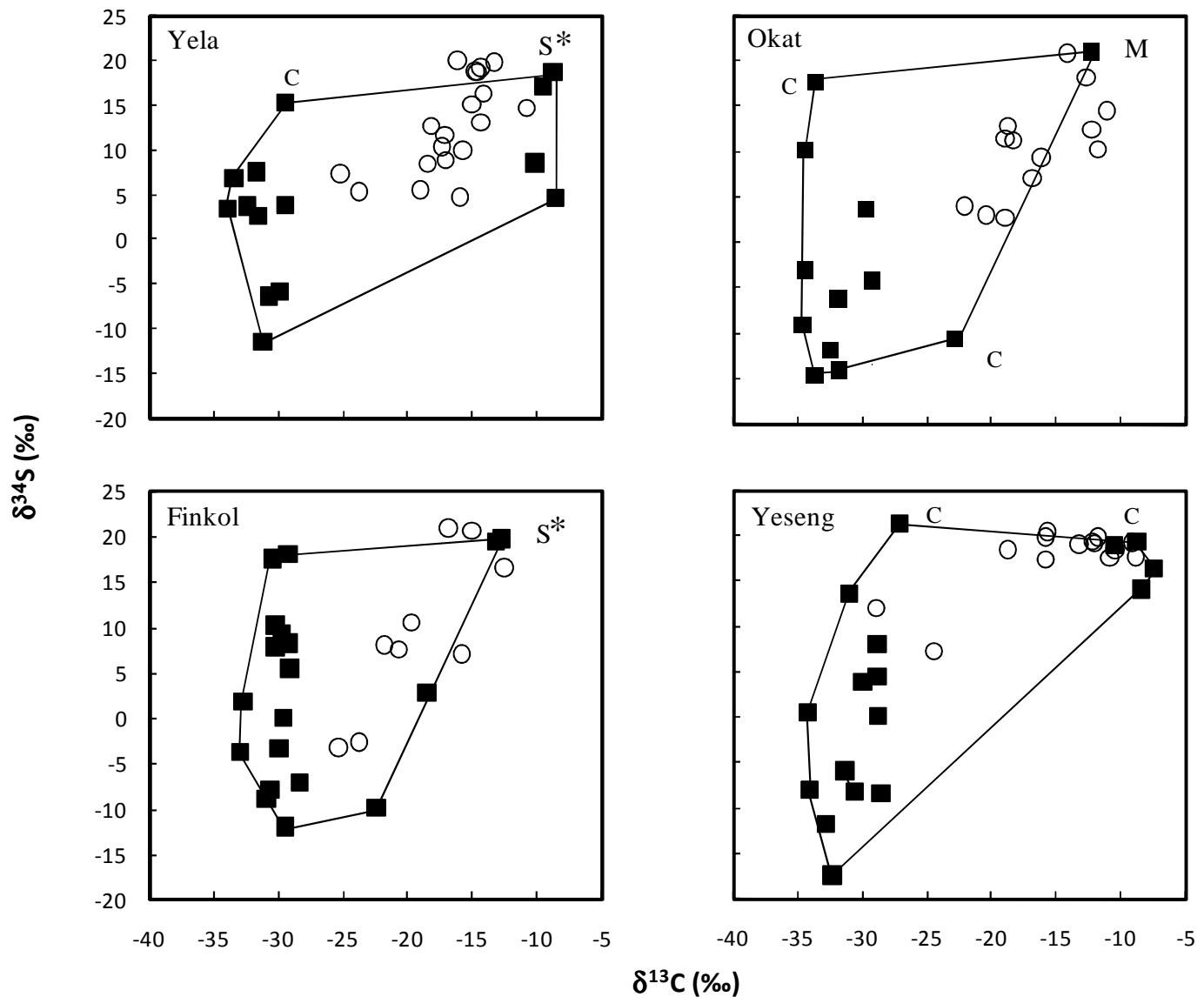

Fig. 1. Graphical solution (convex hull) produced by the model. Stable isotope ratios, $\delta^{34} \mathrm{~S}$ and $\delta^{13} \mathrm{C}$, of organic matter sources (solid squares) and consumer samples (open circles) for the four estuaries of Kosrae (Yela, Okat, Finkol and Yeseng). M refers to mandatory and $\mathrm{C}$ to conditional mandatory organic matter sources. $\mathrm{S}^{*}$ refers to seagrasses.

proportions, in the diet of several consumers. Indeed, for these consumers, when minimizing in the model the value of one of the seagrasses the other takes a high positive value. This can be perceived from the position of the seagrasses $\left(\mathrm{S}^{*}\right)$ in Fig. 1. In other words, if the two seagrasses were considered a single one, i.e., a functional group, it would be conditional mandatory.

In study area Okat, E. acoroides was classified as mandatory source species, i.e., it was present in the diet of all consumers with a minimum contribution of, at least, $28 \%$ in the diet of Scylla serrata, and exceeding half of the diets of $E$. merra (92\%), L. equulus (56\%), Lutjanus fulvus (58\%), Parupeneus indicus (57\%), U. vittatus (63\%) and Siganus randalli (55\%) (Table 2). Barringtonia racemosa, a conditional mandatory source, completes the diet of E. merra with the remaining 8\%. E. acoroides epiphytes (Ep.) also classified as conditional mandatory, was present in the diet of $M$. seheli, L. equulus, L. harak and U. vittatus. The diets of $L$. equulus and $U$. vitattus are fully explained by $E$. acoroides Ep. (44\% and 37\%) combined with E. acoroides (56\% and $63 \%$ ). Additionally, the diet of $M$. seheli consists almost en- tirely of E. acoroides and its epiphytes (52\% minimum of E. acoroides Ep. and $40 \%$ minimum of E. acoroides). E. acoroides Ep. is also present in more than a quarter of the diet of L. harak (Table 2).

In study area Finkol, although there were only optional species, it is possible to conclude that the seagrasses $E$. acoroides or $T$. hemiprichii entered, with relatively high proportions, in the diet of Caranx sp., L. equulus and L. fulvus (Table 3). Note that, similarly to study area Yela, if the two seagrasses were considered a single one it would be conditional mandatory as it can also be perceived from the position of the seagrasses $\left(\mathrm{S}^{*}\right)$ in Fig. 1. From remaining sources $X$. granatum- $\mathrm{R}$ and $X$. granatum- $\mathrm{F}$ had relatively lower importance in the diet of all consumers, as compared to the other sources (Table 3).

Finally, in study area Yeseng, E. acoroides and Lumnitzera littorea-F were part of the diet of several consumers and were thus classified as conditional mandatory. E. acoroides was present in the diet of Myripristis woodsi (values between $26 \%$ and 62\%), L. harak (7\% and 72\%), Abudefduf septemfasciatus (77\% and 98\%) and Acanthurus triostegus 
Table 3. Source category and minimum and maximum proportions of organic matter source species in the diet of consumers at Study Area Fynkol as estimated by stable isotopes $\delta^{13} \mathrm{C}$ and $\delta^{34} \mathrm{~S}$.

\begin{tabular}{|c|c|c|c|c|c|c|}
\hline \multirow[t]{2}{*}{ Source species } & \multirow[t]{2}{*}{ Category } & \multicolumn{5}{|c|}{ Consumer species } \\
\hline & & M. cyprinoides & Caranx sp. & L. equulus & L. fulvus & S. serrata \\
\hline \multicolumn{7}{|l|}{ Mangrove trees } \\
\hline \multirow[t]{2}{*}{ B. gymnorhiza-R } & $\mathrm{O}$ & 0.00 & 0.00 & 0.00 & 0.00 & 0.00 \\
\hline & & 0.41 & 0.32 & 0.31 & 0.42 & 0.29 \\
\hline \multirow[t]{2}{*}{ B. gymnorhiza-I } & $\mathrm{O}$ & 0.00 & 0.00 & 0.00 & 0.00 & 0.00 \\
\hline & & 0.36 & 0.28 & 0.28 & 0.37 & 0.26 \\
\hline \multirow[t]{2}{*}{ B. gymnorhiza-F } & $\mathrm{O}$ & 0.00 & 0.00 & 0.00 & 0.00 & 0.00 \\
\hline & & 0.53 & 0.40 & 0.41 & 0.50 & 0.38 \\
\hline \multirow[t]{2}{*}{ R. apiculata- $\mathrm{R}$} & $\mathrm{O}$ & 0.00 & 0.00 & 0.00 & 0.00 & 0.00 \\
\hline & & 0.57 & 0.32 & 0.43 & 0.40 & 0.42 \\
\hline \multirow[t]{2}{*}{ R. apiculata-I } & $\mathrm{O}$ & 0.00 & 0.00 & 0.00 & 0.00 & 0.00 \\
\hline & & 0.57 & 0.33 & 0.44 & 0.42 & 0.41 \\
\hline \multirow[t]{2}{*}{ R. apiculata-F } & $\mathrm{O}$ & 0.00 & 0.00 & 0.00 & 0.00 & 0.00 \\
\hline & & 0.74 & 0.34 & 0.45 & 0.43 & 0.54 \\
\hline \multirow[t]{2}{*}{$X$. granatum $-\mathrm{R}$} & $\mathrm{O}$ & 0.00 & 0.00 & 0.00 & 0.00 & 0.00 \\
\hline & & 0.25 & 0.24 & 0.23 & 0.31 & 0.22 \\
\hline \multirow[t]{2}{*}{$X$. granatum $-\mathrm{F}$} & $\mathrm{O}$ & 0.00 & 0.00 & 0.00 & 0.00 & 0.00 \\
\hline & & 0.25 & 0.25 & 0.25 & 0.33 & 0.23 \\
\hline \multirow[t]{2}{*}{ S. alba-F } & $\mathrm{O}$ & 0.00 & 0.00 & 0.00 & 0.00 & 0.00 \\
\hline & & 0.43 & 0.34 & 0.33 & 0.45 & 0.31 \\
\hline \multirow[t]{2}{*}{ N. fruticans $-\mathrm{R}$} & $\mathrm{O}$ & 0.00 & 0.00 & 0.00 & 0.00 & 0.00 \\
\hline & & 0.72 & 0.28 & 0.38 & 0.36 & 0.58 \\
\hline \multirow[t]{2}{*}{ N. fruticans-I } & $\mathrm{O}$ & 0.00 & 0.00 & 0.00 & 0.00 & 0.00 \\
\hline & & 0.49 & 0.38 & 0.37 & 0.50 & 0.35 \\
\hline \multicolumn{7}{|c|}{ Freshwater swamp forest trees } \\
\hline \multirow[t]{2}{*}{ T. carolinensis } & $\mathrm{O}$ & 0.00 & 0.00 & 0.00 & 0.00 & 0.00 \\
\hline & & 0.37 & 0.29 & 0.29 & 0.39 & 0.27 \\
\hline \multirow[t]{2}{*}{ H. пипи } & $\mathrm{O}$ & 0.00 & 0.00 & 0.00 & 0.00 & 0.00 \\
\hline & & 0.35 & 0.29 & 0.29 & 0.39 & 0.27 \\
\hline \multirow[t]{2}{*}{ B. racemosa } & $\mathrm{O}$ & 0.00 & 0.00 & 0.00 & 0.00 & 0.00 \\
\hline & & 0.34 & 0.28 & 0.27 & 0.37 & 0.26 \\
\hline \multirow[t]{2}{*}{ Mixed-species leaf litter } & $\mathrm{O}$ & 0.00 & 0.00 & 0.00 & 0.00 & 0.00 \\
\hline & & 0.37 & 0.31 & 0.31 & 0.41 & 0.29 \\
\hline \multicolumn{7}{|l|}{ Seagrasses and epiphytes } \\
\hline \multirow[t]{2}{*}{ E. acoroides } & $\mathrm{O}$ & 0.00 & 0.00 & 0.00 & 0.00 & 0.00 \\
\hline & & 0.26 & 0.64 & 0.57 & 0.53 & 0.28 \\
\hline \multirow[t]{2}{*}{ T. hemprichii } & $\mathrm{O}$ & 0.00 & 0.00 & 0.00 & 0.00 & 0.00 \\
\hline & & 0.26 & 0.65 & 0.58 & 0.54 & 0.29 \\
\hline \multirow[t]{2}{*}{ E. acoroides Ep. } & $\mathrm{O}$ & 0.00 & 0.00 & 0.00 & 0.00 & 0.00 \\
\hline & & 0.68 & 0.30 & 0.40 & 0.37 & 0.74 \\
\hline T. hemprichii Ep. & $\mathrm{O}$ & 0.00 & 0.00 & 0.00 & 0.00 & 0.00 \\
\hline & & 0.46 & 0.52 & 0.69 & 0.66 & 0.57 \\
\hline
\end{tabular}

Letters mean: O - Optional; C - Conditional mandatory; Ep - Epiphytes; R - Riverine; I - Interior; F - Fringe.

(27\% and $82 \%$ ); and L. littoraea-F occurred in the diet of M. woodsi (35\% and 39\%), Caranx sp. (25\% and 56\%), L. monostigma (12\% and 26\%), Parupeneus bifasciatus (9\% and 19\%) and A. triostegus (13\% and 19\%). E. acoroides and $L$. littorea explained, at least, $61 \%$ and $40 \%$ of the diet of M. woodsi and A. triostegus, respectively. Remaining source species were optional. Note that T. hemprichii and $T$. hemprichii epiphytes (Ep.) are the only optional sources that may be significantly present in the diet of $M$. woodsi with a joint contribution that may be up to $39 \%$ (given that minimum contributions of the 2 mandatory sources in the diet of $M$. woodsi are $35 \%$ and 26\%) (Table 4). Note also that T. hemprichii and T. hemprichii Ep. are the optional species with relatively high maximum values in almost all cases (Ta- 
Table 4. Source category and minimum and maximum proportions of organic matter source species in the diet of consumers at Study Area Yeseng as estimated by stable isotopes $\delta^{13} \mathrm{C}$ and $\delta^{34} \mathrm{~S}$.

\begin{tabular}{|c|c|c|c|c|c|c|c|c|c|c|c|c|c|}
\hline \multirow[t]{2}{*}{ Source Species } & \multirow[t]{2}{*}{ Category } & \multicolumn{12}{|c|}{ Consumer Species } \\
\hline & & M. cyprinoides & O. labiosus & M. woodsi & Caranx sp. & L. fulvus & L. monostigma & L. harak & P. bifasciatus & A. septemfasciatus & Oxyeleotris sp. & S. spinus & A. triostegus \\
\hline \multicolumn{14}{|l|}{ Mangrove Trees } \\
\hline \multirow{2}{*}{ B. gymnorhiza- $\mathrm{R}$} & $\mathrm{O}$ & 0.00 & 0.00 & 0.00 & 0.00 & 0.00 & 0.00 & 0.00 & 0.00 & 0.00 & 0.00 & 0.00 & 0.00 \\
\hline & & 0.44 & 0.05 & 0.01 & 0.09 & 0.13 & 0.04 & 0.02 & 0.03 & 0.01 & 0.62 & 0.09 & 0.02 \\
\hline \multirow[t]{2}{*}{ B. gymnorhiza-I } & $\mathrm{O}$ & 0.00 & 0.00 & 0.00 & 0.00 & 0.00 & 0.00 & 0.00 & 0.00 & 0.00 & 0.00 & 0.00 & 0.00 \\
\hline & & 0.32 & 0.04 & 0.01 & 0.06 & 0.09 & 0.03 & 0.02 & 0.02 & 0.00 & 0.46 & 0.07 & 0.01 \\
\hline \multirow[t]{2}{*}{ B. gymnorhiza-F } & $\mathrm{O}$ & 0.00 & 0.00 & 0.00 & 0.00 & 0.00 & 0.00 & 0.00 & 0.00 & 0.00 & 0.00 & 0.00 & 0.00 \\
\hline & & 0.43 & 0.06 & 0.01 & 0.11 & 0.16 & 0.05 & 0.03 & 0.03 & 0.01 & 0.79 & 0.11 & 0.02 \\
\hline \multirow[t]{2}{*}{ R. apiculata- $\mathrm{R}$} & $\mathrm{O}$ & 0.00 & 0.00 & 0.00 & 0.00 & 0.00 & 0.00 & 0.00 & 0.00 & 0.00 & 0.00 & 0.00 & 0.00 \\
\hline & & 0.25 & 0.04 & 0.01 & 0.06 & 0.09 & 0.03 & 0.02 & 0.02 & 0.00 & 0.46 & 0.07 & 0.01 \\
\hline \multirow[t]{2}{*}{ R. apiculata-I } & $\mathrm{O}$ & 0.00 & 0.00 & 0.00 & 0.00 & 0.00 & 0.00 & 0.00 & 0.00 & 0.00 & 0.00 & 0.00 & 0.00 \\
\hline & & 0.26 & 0.03 & 0.01 & 0.06 & 0.08 & 0.02 & 0.02 & 0.02 & 0.00 & 0.41 & 0.06 & 0.01 \\
\hline \multirow[t]{2}{*}{ R. apiculata $-\mathrm{F}$} & $\mathrm{O}$ & 0.00 & 0.00 & 0.00 & 0.00 & 0.00 & 0.00 & 0.00 & 0.00 & 0.00 & 0.00 & 0.00 & 0.00 \\
\hline & & 0.21 & 0.04 & 0.01 & 0.06 & 0.09 & 0.03 & 0.03 & 0.02 & 0.00 & 0.46 & 0.07 & 0.01 \\
\hline \multirow[t]{2}{*}{ L. littorea-F } & C & 0.00 & 0.00 & 0.35 & 0.25 & 0.00 & 0.12 & 0.00 & 0.09 & 0.00 & 0.00 & 0.00 & 0.13 \\
\hline & & 0.71 & 0.12 & 0.39 & 0.56 & 0.40 & 0.26 & 0.05 & 0.19 & 0.03 & 0.45 & 0.16 & 0.19 \\
\hline \multirow[t]{2}{*}{ S. alba-I } & O & 0.00 & 0.00 & 0.00 & 0.00 & 0.00 & 0.00 & 0.00 & 0.00 & 0.00 & 0.00 & 0.00 & 0.00 \\
\hline & & 0.32 & 0.05 & 0.01 & 0.09 & 0.13 & 0.04 & 0.03 & 0.03 & 0.01 & 0.64 & 0.09 & 0.02 \\
\hline \multirow[t]{2}{*}{ N. fruticans $-\mathrm{R}$} & $\mathrm{O}$ & 0.00 & 0.00 & 0.00 & 0.00 & 0.00 & 0.00 & 0.00 & 0.00 & 0.00 & 0.00 & 0.00 & 0.00 \\
\hline & & 0.30 & 0.04 & 0.01 & 0.07 & 0.10 & 0.03 & 0.02 & 0.02 & 0.01 & 0.50 & 0.07 & 0.01 \\
\hline \multirow[t]{2}{*}{ N. fruticans-I } & O & 0.00 & 0.00 & 0.00 & 0.00 & 0.00 & 0.00 & 0.00 & 0.00 & 0.00 & 0.00 & 0.00 & 0.00 \\
\hline & & 0.20 & 0.03 & 0.01 & 0.05 & 0.07 & 0.02 & 0.02 & 0.01 & 0.00 & 0.35 & 0.05 & 0.01 \\
\hline \multicolumn{14}{|l|}{ Freshwater Swamp trees } \\
\hline \multirow[t]{2}{*}{ T. carolinensis } & $\mathrm{O}$ & 0.00 & 0.00 & 0.00 & 0.00 & 0.00 & 0.00 & 0.00 & 0.00 & 0.00 & 0.00 & 0.00 & 0.00 \\
\hline & & 0.48 & 0.06 & 0.01 & 0.11 & 0.15 & 0.04 & 0.03 & 0.03 & 0.01 & 0.75 & 0.10 & 0.02 \\
\hline \multirow[t]{2}{*}{ B. racemosa } & $\mathrm{O}$ & 0.00 & 0.00 & 0.00 & 0.00 & 0.00 & 0.00 & 0.00 & 0.00 & 0.00 & 0.00 & 0.00 & 0.00 \\
\hline & & 0.85 & 0.08 & 0.03 & 0.24 & 0.32 & 0.10 & 0.03 & 0.07 & 0.02 & 0.49 & 0.12 & 0.04 \\
\hline \multirow[t]{2}{*}{ Mixed-species leaf litter } & $\mathrm{O}$ & 0.00 & 0.00 & 0.00 & 0.00 & 0.00 & 0.00 & 0.00 & 0.00 & 0.00 & 0.00 & 0.00 & 0.00 \\
\hline & & 0.59 & 0.08 & 0.02 & 0.14 & 0.20 & 0.06 & 0.03 & 0.04 & 0.01 & 0.68 & 0.12 & 0.03 \\
\hline \multicolumn{14}{|l|}{ Seagrasses and epiphytes } \\
\hline \multirow[t]{2}{*}{ E. acoroides } & $\mathrm{C}$ & 0.00 & 0.00 & 0.26 & 0.00 & 0.00 & 0.00 & 0.07 & 0.00 & 0.77 & 0.00 & 0.00 & 0.27 \\
\hline & & 0.12 & 0.93 & 0.62 & 0.51 & 0.68 & 0.78 & 0.72 & 0.83 & 0.98 & 0.38 & 0.92 & 0.82 \\
\hline \multirow[t]{2}{*}{ T. hemprichii } & $\mathrm{O}$ & 0.00 & 0.00 & 0.00 & 0.00 & 0.00 & 0.00 & 0.00 & 0.00 & 0.00 & 0.00 & 0.00 & 0.00 \\
\hline & & 0.13 & 0.92 & 0.40 & 0.55 & 0.74 & 0.85 & 0.42 & 0.91 & 0.22 & 0.41 & 0.87 & 0.60 \\
\hline \multirow[t]{2}{*}{ E. acoroides Ep. } & $\mathrm{O}$ & 0.00 & 0.00 & 0.00 & 0.00 & 0.00 & 0.00 & 0.00 & 0.00 & 0.00 & 0.00 & 0.00 & 0.00 \\
\hline & & 0.11 & 0.20 & 0.04 & 0.37 & 0.52 & 0.15 & 0.32 & 0.10 & 0.03 & 0.36 & 0.38 & 0.07 \\
\hline \multirow{2}{*}{ T. hemprichii Ep. } & $\mathrm{O}$ & 0.00 & 0.00 & 0.00 & 0.00 & 0.00 & 0.00 & 0.00 & 0.00 & 0.00 & 0.00 & 0.00 & 0.00 \\
\hline & & 0.11 & 0.38 & 0.08 & 0.44 & 0.60 & 0.27 & 0.60 & 0.19 & 0.05 & 0.36 & 0.70 & 0.12 \\
\hline
\end{tabular}

Letters mean: O - Optional; C - Conditional mandatory; Ep - Epiphytes; R - Riverine; I - Interior; F - Fringe.

ble 4). This may imply the relevance of these sources in the diet of several consumers. Also in this case, differences between $E$. acoroides and $T$. hemprichii in the isotopic signature of $\delta^{13} \mathrm{C}$ were sufficient to allow discrimination between the two seagrasses and conclude that $E$. acoroides was present in the diet of some consumers (conditional mandatory).

\section{Discussion}

Our results confirmed the importance of seagrasses and their epiphytes as food sources in a riverine tropical fishery, as shown by others investigating food chains in tropical streams (e.g. Brito et al., 2006; Benstead et al., 2006; Moncreiff and Sullivan, 2001). In addition we showed the most relevant sources in the diet of consumers. For instance, we concluded that $E$. acoroides was present in the diet of all (e.g. study area Okat) or several consumers (e.g. study area Yeseng) and that epiphytes of $E$. acoroides were part of the diet of several consumers (e.g. study area Okat).

The majority of species were classified as optional. This result could be expected in unconstrained mixing models with a number of sources much higher than that of markers, and when several different samples (consumers) are considered simultaneously. However, because the model indicated minimum and maximum proportions of sources in the con- sumers, it also generated relevant information from optional sources that considerably improved the interpretation of results. Thus, we were able to show that there were two main mangrove litter source species (X. granatum and L. littorea) contributing to the consumer diets and to identify those consumers for which mangrove litter sources were not dietary relevant. Contribution of litter from freshwater swamp-forest was relatively low. Adding to the limited contribution of Terminalia carolinensis to the food webs of the estuaries analysed (as shown by Benstead et al., 2006), we also shown that litter of B. racemosa, another fresh-water swamp tree, was certainly included (although in low quantities) in the diet of E. merra in study area Okat.

Our model has the computational ability to analyse any number of individual sources but the value of the output is likely to be higher if discrimination of stable isotope signatures among sources increases. For instance, in area Yeseng, stable isotope discrimination along the $\delta^{13} \mathrm{C}$ was sufficient to allow discrimination between seagrasses leading us to conclude that $E$. acoroides was the dominant seagrass in the diet of different consumers. However, in study areas Yela and Finkol, it was not possible to assess which seagrass was mainly contributing to the consumer diets. In this case, $E$. acoroides and T. hemprichii had similar tracer signatures and function roles in the consumer diets and should be considered as a group. 
The existence of correlations between contributions of sources to the mixtures makes the ranges of each source dependent of each other. This needs careful interpretation, particularly within groups, as in sources with similar isotopic signatures, the maximum contribution of one source often implies poor contributions of the others. Although this cannot be immediately revealed from analysis of Tables 1 to 4 , which only show the maximum and minimum values of each source among the infinite list of feasible solutions, analysis of the solutions produced by our model (the Excel long output sheet produced by the model available at http://www.isa.utl.pt/ orestes/LP_Tracer/) would easily identify this type of correlations among sources. Such analysis, for example, would allow to conclude that a "group is mandatory" (i.e., at least one of its members enters in every mixture) in spite of none of its members being classified as mandatory. This was the case of the seagrasses $E$. acoroides and T. hemprichii in study areas Yela and Fynkol.

Graphical interpretation may also help decisions on grouping of sources with similar isotopic signatures, but for more than 3 markers methods such as the Nearest Neighbourhood Distance (Lubetkin and Simenstad, 2004) or other multivariate statistical criteria must be used. Grouping, however, must be considered and interpreted carefully. For instance, statistical meaningful groups may not correspond to ecologically functional groups (e.g. Mayes and Dove, 2000). Also, a priori grouping may lead to exclusion of samples from the convex polygon as it happened with Megalops cyprinoides in study areas Yeseng and Finkol (Benstead et al., 2006).

The model presented here suggests a computationally efficient way to classify and generate minimum and maximum contributions of stable isotopes to multiple sources simultaneously. The model identified those sources that were important, unimportant or composed a substantial proportion of the consumer diets, but was also able to explain most of the diet of some consumers (e.g. M. woodsi in study area Yeseng). This contrasts with Benstead et al. (2006) contention that natural-abundance isotope surveys are powerful in disproving the importance of certain sources, but usually weak in showing the importance of a source of interest.

Contrary to other methods the model presented here addresses multiple samples simultaneously. In the present case we have dealt with multiple samples of different identities (i.e. primary consumers) but the approach is also suited for cases where several replicates of a population are present. Our approach gives information on the proportional contributions of sources to mixtures and qualitatively classifies the samples within the convex hull of solutions. Those consumer solutions that are infeasible (i.e. outside the convex hull) are identified and can be excluded from analysis. Solutions may be infeasible due to uncertainty that include measurement error, fractionation, or multiple tissue types. The tolerance of the model, however, can be altered to accept infeasible solutions that may be ecologically sensible. This is an approach that can be complemented by Bayesian methods (e.g. Moore and Semmens, 2008). Indeed, a consumer solution, may plausibly reside in the feasible solution space after accounting for sources of uncertainty and this may be accounted for using Bayesian-mixing models that estimate probability distributions for the proportional source contributions to a consumer (Moore and Semmens, 2008; Parnell, 2008). Whilst the Bayesian analysis places probabilities on solutions with uncertainty included, the convex hull analysis either accepts or rejects potential solutions based on their feasibility with uncertainty ignored.

The importance of using stable isotopes as tracers in ecological research is increasingly rapidly. Strong limitation of stable isotopes arises when dealing with numbers of sources higher than those of isotope tracers. In such cases, an approach such as the one shown in the present paper provides qualitative and quantitative information contributing to data interpretation. The model may contribute to data interpretation in other kind of problems. For instance, within the context of climate change scenarios, particular sets of organic matter sources may disappear or become less available within the ecosystem. In such cases, the model would allow simulation of alternative diets and assessment of the relatively importance of substitute sets of organic matter sources to consumers, a potentially relevant information for managers and decision makers. Additionally the model can handle any number of markers which may also contribute for extending the scope of stable isotopes to a range of new questions dealing with multiple sources and multiple tracers.

Acknowledgements. We thank J. Benstead for permission to use Kosrae data and P. M. Eldridge and G. Hosack and a anonymous referee for valuable comments on the manuscript. MNB was funded by the Portuguese Foundation for Science and Technology (FCT) grant SFRH/BPD/27216/2006 and MCC by SFRH/BPD $38710 / 2007$ and the projects POCTI/AGG/48704/2002 and POCTI/AGR/63322/2004. JOC was supported by program POCTI of FCT.

Edited by: J. Middelburg

\section{References}

Barcia, P., Bugalho, M. N., Campagnolo, M. L., and Cerdeira, J. O.: Using $\mathrm{N}$-alkanes to estimate the diet composition of herbivores, Animal (Farming Systems and Environment), 1, 141-149, 2007.

Ben-David, M., Flynn, R. W., and Schell D. M.: Annual and seasonal changes in diets of martens: evidence from stable isotope analysis, Oecologia, 111, 280-291, 1997.

Benstead, J. P., March J. G., Fry, B., Ewel, K. C., and Pringle, C. M.: Testing IsoSource: stable isotope analysis of a tropical fishery with diverse organic matter sources, Ecology, 87, 327-333, 2006.

Brito, E. F., Moulton, T. P., Souza, M. L., and Bunn, S. E.: Stable isotope analysis indicates microalgae as the predominant food source of fauna in a coastal forest stream, south-east Brazil: Austral Ecol., 31, 623-633, 2006.

Cerling, T. E., Wittemyer G., Rasmussen, H. B., Vollrath, F., Cerling, C. E., Robinson, T. J., and Douglas-Hamilton, I.: Stable 
isotopes in elephant hair document migration patterns and diet changes, P. Natl. Acad. Sci. USA, 103, 371-373, 2006.

Cherel, Y., Hobson, K. A., Bailleul, F. R., and Groscolas, R.: Nutrition, physiology, and stable isotopes: new information from fasting and molting penguins, Ecology, 86, 2881-2888, 2005.

Dawson, T. E., Mambelli, S., Plamboeck, A. H., Templer, P. H., and Tu, K. P.: Stable isotopes in plant ecology, Ann. Rev. Ecol. Syst., 33, 507-559, 2002.

Demopoulos, A. W. J., Fry, B., and Smith, C. R.: Food-web structure in exotic and native mangroves - a Hawaii-Puerto Rico comparison, Oecologia, 153, 675-686, 2007.

Inger, R., Ruxton, G. D., Newton, J., Colhoun, K., Robinson, J. A., Jackson A. L., and Bearhop, S.: Temporal and intrapopulation variation in prey choice of wintering geese determined by stable isotope analysism, J. Anim. Ecol., 75, 1190-1200, 2006.

Lubetkin, S. C. and Simenstad, C. A.: Multi-source mixing models to quantify food web sources and pathways, J. Appl. Ecol., 41, 996-1008, 2004.

Mayes, R. W. and Dove, H.: Measurement of dietary nutrient intake in free-ranging mammalian herbivores, Nutr. Res. Rev., 13, 107$138,2000$.

McKechnie, A. E.: Stable isotopes: powerful new tools for animal ecologists, S. Afr. J. Sci., 100, 131-134, 2004.
Moncreiff, C. A. and Sullivan, M. J.: Trophic importance of epiphytic algae in subtropical seagrass beds: evidence from multiple stable isotope analyses, Mar. Ecol. Progr. Ser., 215, 93-106, 2001.

Moore, J. W. and Semmens, B. X.: Incorporating uncertainty and prior information into stable isotope mixing models, Ecol. Lett., 11, 470-480, 2008.

Parnell, A.: The siar Package: stable isotope analysis in $\mathrm{R}$, available at: http://cran.r-project.org/web/packages/siar/siar.pdf, last access: 17 September 2008.

Phillips, D. L. and Gregg, J. W.: Source partitioning using stable isotopes: coping with too many sources, Oecologia, 136, 261269, 2003.

Querejeta, J. I., Estrada-Medina, H., Allen, M. F., and JiménezOsornio, J. J.: Water source partitioning among trees growing on shallow karst soils in a seasonally dry tropical climate, Oecologia, 152, 26-36, 2007.

van Dover, C. L., Grassler, J. F., Fry, B., Garritt, R. H., and Starczak, V. R.: Stable isotope evidence for entry of sewage-derived organic material into a deep-sea food web, Nature, 360, 153-155, 1992.

West, J. B., Bowen, G. J., Cerling, T. E., and Ehleringer, J. R.: Stable isotopes as one of nature's ecological recorders, Trends Ecol. Evol., 21, 408-414, 2006. 